\title{
Behaviour of Batter Micropiles Subjected to Vertical and Lateral Loading Conditions
}

\author{
Binu Sharma, Zakir Hussain \\ Department of Civil Engineering, Assam Engineering College, Guwahati, India \\ Email: binusharma78@gmail.com
}

How to cite this paper: Sharma, B., \& Hussain, Z. (2019). Behaviour of Batter Micropiles Subjected to Vertical and Lateral Loading Conditions. Journal of Geoscience and Environment Protection, 7, 206-220.

https://doi.org/10.4236/gep.2019.72014

Received: January 2, 2019

Accepted: February 25, 2019

Published: February 28, 2019

Copyright $\odot 2019$ by author(s) and Scientific Research Publishing Inc. This work is licensed under the Creative Commons Attribution International License (CC BY 4.0).

http://creativecommons.org/licenses/by/4.0/

\begin{abstract}
Micropiles are drilled and grouted piles having diameter between 100 to 250 $\mathrm{mm}$. Due to its small diameter, it is suitable for low headroom and limited work area conditions. It can be installed without noise nuisance, without vibrations to surrounding soils and structures and without disruption to the production operations in industries which makes micropiles suitable for underpinning and seismic retrofitting of structures. It is necessary to therefore understand the behaviour of micropiles under different loading conditions. This work is on vertical and battered micropiles with different length/diameter ratio (L/D) subjected to vertical and lateral loading conditions. Batter angles had a significant influence on both the vertical and lateral load carrying capacity. The ultimate vertical load was found to increase upto a $30^{\circ}$ batter. The ultimate lateral load was found to increase significantly with increasing L/D ratios upto an L/D ratio of 30 for vertical and 48 for battered piles, beyond which the increase was found to be not significant. In general, negative battered micropiles offered more lateral resistance than positive battered micropiles. The results of the study indicated that the ultimate load capacity and mode of failure of the micropiles are a function of the angle of batter, direction of batter and the $\mathrm{L} / \mathrm{D}$ ratio for vertically and laterally loaded micropiles.
\end{abstract}

\section{Keywords}

Batter Micropiles, Vertical Load, Lateral Load, Length to Diameter Ratio, Failure Mechanism

\section{Introduction}

Micropiles have been in use for more than 50 years. Originally, they were conceived as innovative solutions to aid in difficult post war reconstruction efforts. Over the past 20 years, micropile technology has expanded significantly and has evolved from the concept of low capacity micropile networks to the use of single, 
high capacity elements. These small elements allow engineers to solve some difficult structural support problems involving high loads and restricted access. Engineers and researchers are now giving renewed attention to micropile networks as technically and economically viable solutions to problems of slope stabilization, lateral loading and seismic retrofit.

Micropile is a very flexible pile. Due to its high slenderness ratio and its ductile steel core, it can exhibit flexible behaviour under dynamic loading and can be used for seismic retrofitting of structures. In Italy foundation with root pile have already survived several earthquake of high intensity. In very recent years the use of micropiles for seismic retrofitting of existing foundations has been investigated by Public Work Research Institute (PWRI), Japan. Through joint research with 13 other private companies, PWRI has confirmed that micropile method for seismic retrofitting has superior execution properties under severe condition.

The significance of micropiles in soil reinforcement and in retrofitting and underpinning works are reported in literature by various researchers (Schlosser \& Juran, 1979; Sabini \& Sapio, 1981; Lizzi, 1978; Lizzi, 1982; Lizzi, 1983; Soliman \& Munkofh, 1988; O’Neil \& Pierry, 1989; Ting \& Nithiraj, 2000; Bruce, 1995; Noorzad \& Saghaee, 2009). Noorzad \& Saghaee (2009) studied the effect of inclined micropiles under seismic loading using numerical methods. Their analysis showed that inclined micropiles performed well under seismic loading. The inclined micropiles showed an increase in axial force and a decrease in shear force and bending moments with increasing batter angle due to seismic loading. Sadek \& Isam (2004) provided valuable information about the influence of micropiles inclination on dynamic amplification and on the seismic-induced internal forces in micropiles. Inclined grouted micropiles were also investigated through centrifuge test to study its effect on liquefaction remediation of soils (Mitrani \& Madabhushi, 2005). Seismic behaviour of micropiles was also investigated by many investigators (Benslimane et al., 1998; Juran et al., 2001; Yamane et al., 2000). Micropile behaviour through model testing is also reported by various researchers (Sharma, 2011; Polous \& Davis, 1980; Manfared, 2012; Broms, 1964).

The work on batter micropiles is limited as compared to vertical micropiles. In literature, experimental data on batter micropiles are rather scarce compared to that of vertical piles. This work is a parametric study on the behaviour of batter micropiles through model testing. This paper examines and presents the effect of batter angles of single micropiles on the ultimate vertical and lateral load carrying capacity in sand with a relative density of $50 \%$. Though it is more common to utilize multiple or groups of micropiles (vertical and/or battered), it is of interest to study a single battered micropile subjected to vertical and lateral loading to better understand group behaviour. The prime objective of this study was to provide the experimental database to developed and evaluate design methods for engineering applications like slope stabilization, retaining systems and seismic retrofitting of foundations. 


\section{Experimental Model}

\subsection{Properties of Sand}

Dry sand was used for the model experimental study. The physical properties of the sand used are shown in Table 1 . The dry sand was placed inside a model tank with physical dimensions of $1.7 \mathrm{~m} \times 1.5 \mathrm{~m} \times 0.93 \mathrm{~m}$. To fill up the tank at a uniform relative density, the rainfall technique was utilized. Initially a strainer was fixed at a height of $60 \mathrm{~cm}$ above the tank. Then sand was allowed to fall under gravity through the strainer till a height of $5 \mathrm{~cm}$ was filled up in the tank. After filling up $5 \mathrm{~cm}$, the strainer was lifted up by the same height of $5 \mathrm{~cm}$ in order to maintain a uniform relative density of $50 \%$. In this process the whole tank was filled up keeping the height of fall constant. It was determined that when the height of fall was $60 \mathrm{~cm}$, the obtained relative density of the sand was $50 \%$ which correlates to a unit weight of $16 \mathrm{kN} / \mathrm{m}^{3}$.

\subsection{Loading Arrangement}

The vertical and lateral loads were applied to the grouted piles by a mechanical jack system connected to a proving ring. The different loads applied to the soil sample are obtained from the dial gauge readings attached to the proving ring with a constant of $0.99 \mathrm{~kg}(9.8 \mathrm{~N}) /$ division. The other end of the proving ring was fixed to the top of the pile cap by a ball-and-socket arrangement for vertical loading shown in Figure 1(a). In case of lateral loading the proving ring was fixed to the side of the pile cap by ball and socket arrangement as shown in Figure $1(\mathrm{~b})$.

\section{Micropiles-Properties and Installation}

The model piles were grouted by an aluminium casing pipe having an outside and inside diameter of $1.2 \mathrm{~cm}$ and $1.0 \mathrm{~cm}$ respectively. The reinforcing element consisting of a $1.5 \mathrm{~mm}$ diameter mild steel rod was placed inside the casing pipe. A $60^{\circ}$ wooden conical shoe was attached to the bottom of the casing pipe to prevent sand from entering the casing during installation. The aluminium casing pipe, steel rod and wooden shoe were manually pushed as a unit into the sand in the model tank using a template made from a hollow wooden box with a hole at the top and bottom of the box. The two holes were aligned such that the desired inclination was obtained throughout installation. Maintaining a fluid head of $100 \mathrm{~cm}$ inside the casing as it was extracted in $2 \mathrm{~cm}$ lifts; the pile was grouted using a cement slurry mixture with a water cement ratio of 0.5 . This process was repeated until the pile was grouted and the casing extracted. In order to have a free standing micropile, after grouting of the pile was completed, a $50 \mathrm{~mm}$ long aluminium pipe was attached to the top of the micropile at the ground surface essentially centering the steel rod in the casing. Additional cement slurry was poured into the pipe. Figure 2 shows the grouted batter micropiles in the model box. 
Table 1. Properties of the model sand at $50 \%$ relative density.

\begin{tabular}{cc}
\hline Physical properties & Value \\
\hline Effective grain size, $\mathrm{d}_{\mathrm{eff}}$ & 0.23 \\
Uniformity coefficient, $\mathrm{C}_{\mathrm{u}}$ & 2.08 \\
Coefficient of curvature, $\mathrm{C}_{\mathrm{c}}$ & 0.96 \\
Specific gravity, $\mathrm{G}_{\mathrm{s}}$ & 2.66 \\
Maximum void ratio, $\mathrm{e}_{\max }$ & 0.88 \\
Minimum void ratio, $\mathrm{e}_{\min }$ & 0.68 \\
Unit weight & $16 \mathrm{kN} / \mathrm{m}^{3}$ \\
Angle of internal friction, $\phi$ & $38^{\circ}$ \\
\hline
\end{tabular}

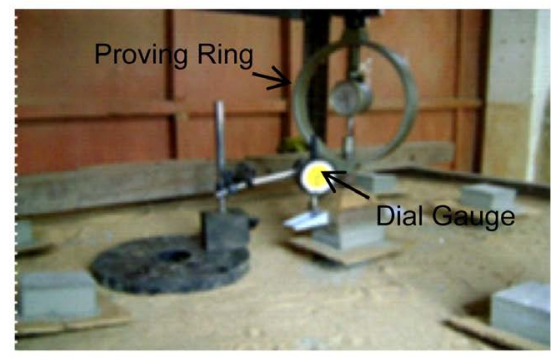

(a)

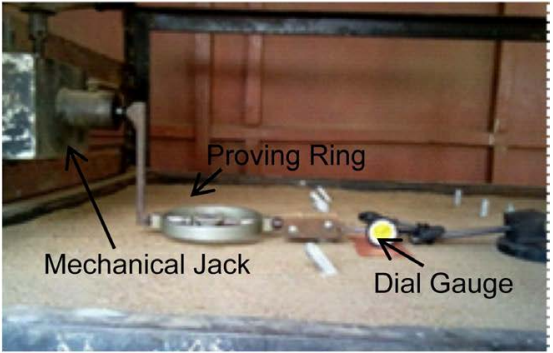

(b)

Figure 1. (a) Setup for Vertical Loading; (b) Setup for Lateral Loading.

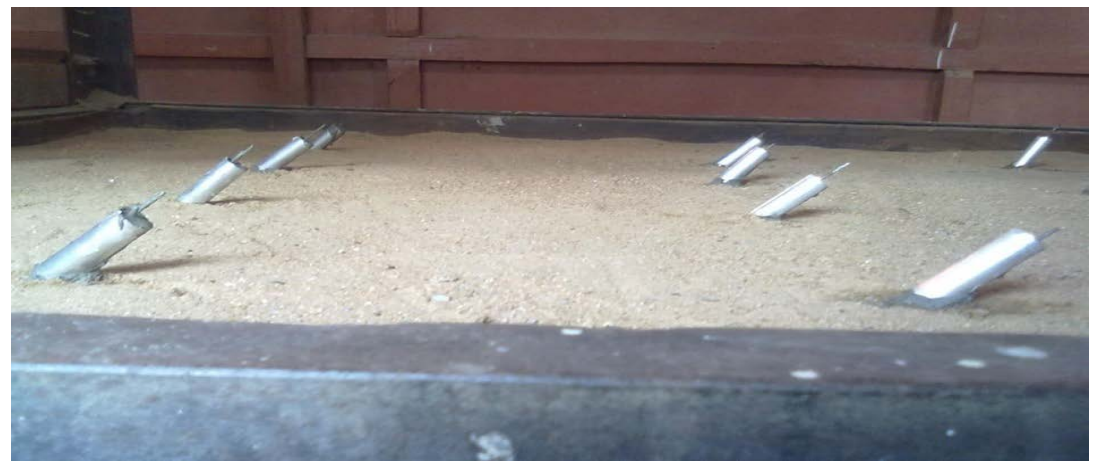

Figure 2. Phtograph of the grouted batter micropiles.

\section{Test Results}

\subsection{Battered Micropiles Subjected to Vertical Load}

To understand the behaviour of battered micropiles subjected to vertical loads, 36 free head micropiles with 4 different batter angles $\left(0^{\circ}, 15^{\circ}, 30^{\circ}\right.$ and $\left.45^{\circ}\right)$ were installed in the model tank. All the 36 micropiles with 4 different batter angles were loaded vertically. For $0^{\circ}$ and $15^{\circ}$ batter, lengths to diameter (L/D) ratios chosen were $12,18,24,30,36,42,48,56,62$ and 68 . The length to diameter ratios chosen for $30^{\circ}$ and $45^{\circ}$ batter was $12,18,24,30,36,42,48$ and 56 . The vertical micropiles $\left(0^{\circ}\right.$ batter) with the respective L/D ratio were chosen for comparison of the behaviour of the battered micropiles. Figure 3 depicts the ultimate 


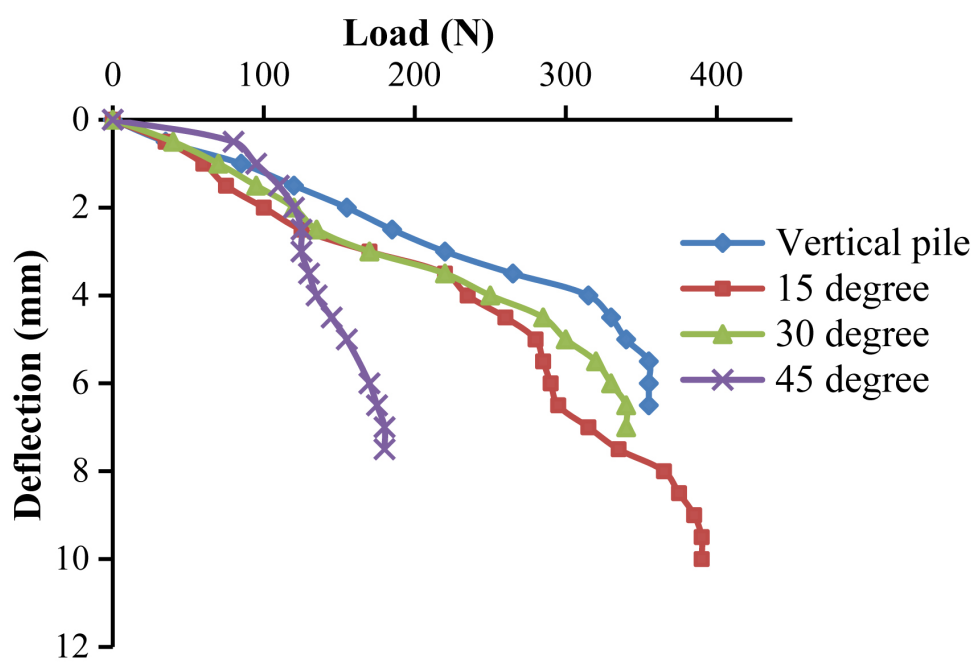

Figure 3. Ultimate vertical load versus vertical displacement for L/D ratio of 42.

vertical load and vertical displacement characteristics of micropiles having L/D ratio of 42 for batter angles of $0^{\circ}, 15^{\circ}, 30^{\circ}$ and $45^{\circ}$. For the purpose of this experiment, ultimate vertical load of pile under vertical load has been taken as the point on the vertical load versus vertical displacement curve at which the curve maintains a continuous vertical displacement increase with no further increase in vertical load.

\subsubsection{Effect of Length to Diameter Ratio and Pile Batter Angle}

The variation of the ultimate vertical load with $\mathrm{L} / \mathrm{D}$ ratio for the different batter angles is shown in Figure 4. Similarly the variation of the ultimate vertical load with the pile batter angles for various L/D ratios is shown in Figure 5. The micropiles at $15^{\circ}$ batter achieved the largest ultimate load. For $30^{\circ}$ batter it came out to be slightly lower than vertical piles. It is further observed that the ultimate vertical load increased with an increase in L/D ratio of the piles. The ultimate vertical load is minimum for $45^{\circ}$ batter and it is found to be quite less compared to $15^{\circ}$ and $30^{\circ}$ batter. The effect of $\mathrm{L} / \mathrm{D}$ ratio for $45^{\circ}$ batter is significant upto $\mathrm{L} / \mathrm{D}$ ratio of 30 . Beyond 30, the ultimate load is not significant. This shows that there is no effect of increase in $\mathrm{L} / \mathrm{D}$ ratio on the ultimate vertical load in case of $45^{\circ}$ batter. A possible reason for increase in ultimate load at $15^{\circ}$ batter may be due to the passive soil resistance. This is true upto a particular batter angle beyond which the failure of the piles are mostly governed by structural and stiffness considerations of the piles.

The percentage increase or decrease of the ultimate load of the batter piles with respect to the vertical piles are tabulated in Table $2.15^{\circ}$ batter pile is showing an average percentage increase of $11.75 \%$ of ultimate pile load in comparison to the vertical pile whereas $30^{\circ}$ and $45^{\circ}$ batter piles are showing an average percentage decrease of $9.5 \%$ and $52.04 \%$ respectively. The results show that upto $30^{\circ}$ batter angle, there is no significant increase or decrease of the ultimate vertical pile load with respect to the vertical pile. This implies that for the design 


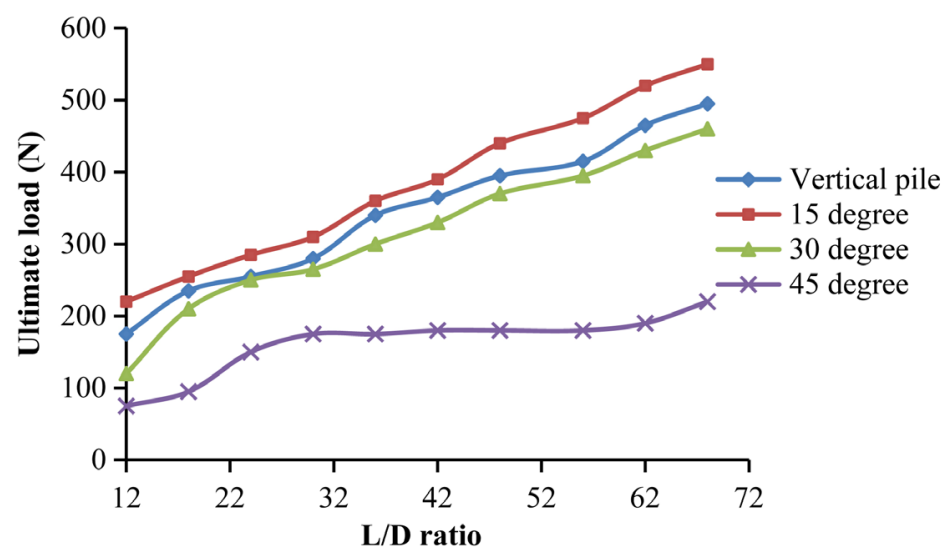

Figure 4. Ultimate vertical load versus L/D ratio.

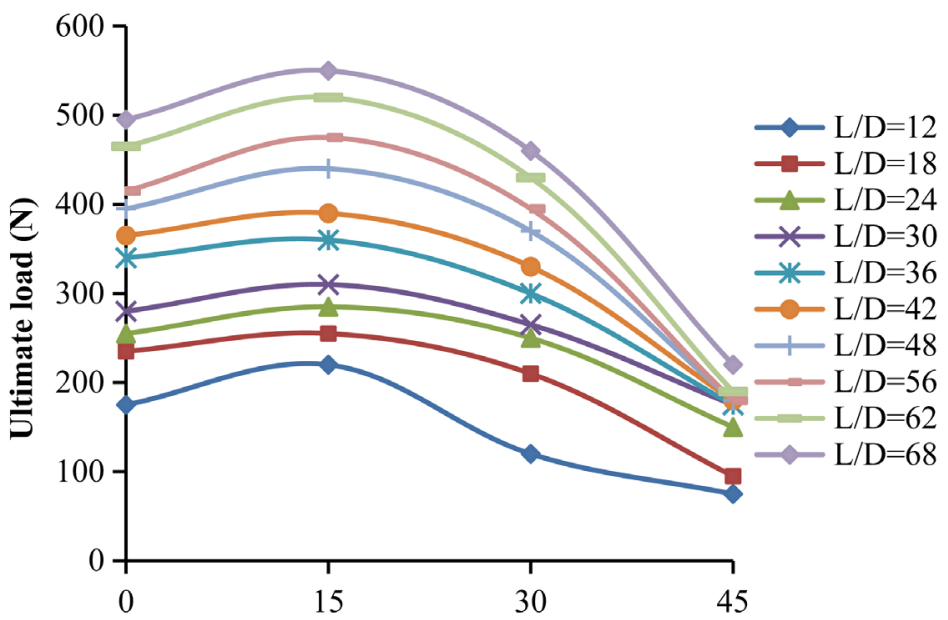

Pile batter angle (degree)

Figure 5. Ultimate vertical load versus pile batter angle.

Table 2. Variation of the batter pile load with respect to the vertical pile.

\begin{tabular}{cccccccc}
\hline L/D ratio & \multicolumn{3}{c}{ Ultimate load (N) } & \multicolumn{3}{c}{ Variation of batter pile load with respect to the vertical pile } \\
\hline & \multicolumn{1}{c}{$0^{\circ}$} & $15^{\circ}$ & $30^{\circ}$ & $45^{\circ}$ & $15^{\circ}$ & $30^{\circ}$ & \% decrease \\
\hline 12 & 175 & 220 & 120 & 75 & 25.71 & 57.14 & $45^{\circ}$ \\
18 & 235 & 255 & 210 & 95 & 7.84 & 31.43 & 57.14 \\
24 & 255 & 285 & 250 & 150 & 11.76 & 1.96 & 41.18 \\
30 & 280 & 310 & 265 & 175 & 10.71 & 5.38 & 37.50 \\
36 & 340 & 360 & 300 & 175 & 5.88 & 11.76 & 48.53 \\
42 & 365 & 390 & 330 & 180 & 6.85 & 9.59 & 50.68 \\
48 & 395 & 440 & 370 & 180 & 11.39 & 6.33 & 54.43 \\
56 & 415 & 475 & 395 & 180 & 14.45 & 4.82 & 56.63 \\
62 & 465 & 520 & 430 & 190 & 11.83 & 7.53 & 59.14 \\
68 & 495 & 550 & 460 & 220 & 11.11 & 7.07 & 55.56 \\
& \multicolumn{3}{c}{ Average (\%) } & & 11.75 & 9.5 & 52.04 \\
\hline
\end{tabular}


of a batter micropile upto $30^{\circ}$ batter angle subjected to vertical loading, it can be assumed that the micropile is capable of resisting the same vertical load as a vertical micropile of the same type and size and driven to the same stratum.

\subsubsection{Mode of Failure}

Applied vertical loads in micropiles are mainly resisted by skin friction component with minimum end bearing component. Again due to the micropiles small cross sectional area the micropile design is more frequently governed by structural and stiffness considerations. Hence in case of battered micropiles, the mode of failure in the micropiles assumes significance. The mode of failure can be either geotechnical or soil failure and structural failure. In the battered micropiles tested, both geotechnical and structural failures were observed. The mode of failure is found to be a function of the pile batter angle and L/D ratio of the piles which is depicted in Figure 6. For the vertical piles, for L/D ratios upto 42 , the piles fail by geotechnical failure (soil failure) and for L/D ratios above 42 , the piles fail by structural failure. As the pile batter angle increased, structural failure was the controlling mode of failure at lower L/D ratios. For the piles battered at $45^{\circ}$ and with an L/D ratio greater than 30 the piles failed by structural failure at about the same ultimate load (Figure 4 and Figure 5). In short for vertically loaded piles, increasing the length of a pile with large angles of batter will not increase the ultimate load. Figure 7 shows the photograph of the exhumed piles with the modes of failure for the vertical micropiles and varying L/D ratio.

Observation of Figure 6 shows that fewer micropiles underwent geotechnical failure as the pile batter angle increased, which may be explained by the mobilisation of passive soil resistance. After a particular increase in pile batter angle the failure of the piles are mostly governed by structural and stiffness considerations of the piles.

\subsection{Battered Micropiles Subjected to Lateral Load}

Information on single battered micropiles subjected to lateral loading is rare. The behaviour of single battered micropiles subjected to lateral loads have been studied through model testing and compared with the behaviour of vertical micropiles. For this study, a total of 50 micropiles were installed, grouted and tested. The angles of batters used for the experiments were $+15^{\circ}$ and $+30^{\circ}$ positive batter and $-15^{\circ}$ and $-30^{\circ}$ negative batter. Positive batter (i.e., opposite to the direction of loading) and negative batter (i.e., in the same direction of loading) micropiles are shown in Figure 8. Laterally loaded piles exhibit rigid and flexible behaviour. To study this behaviour, the $\mathrm{L} / \mathrm{D}$ ratios selected for study were 12,18 , $24,30,36,42,48,56,62$ and 68 . The ultimate lateral load-deflection behaviour of micropiles having L/D ratio of 42 for variable batter angles is shown in Figure 9 where it is clear that the load-displacement relationship is nonlinear.

For the purpose of this experiment, the ultimate lateral resistance of the micropiles is defined as the point on the load displacement curve at which there is a continuous increase in displacement with no further increase in lateral load. For 


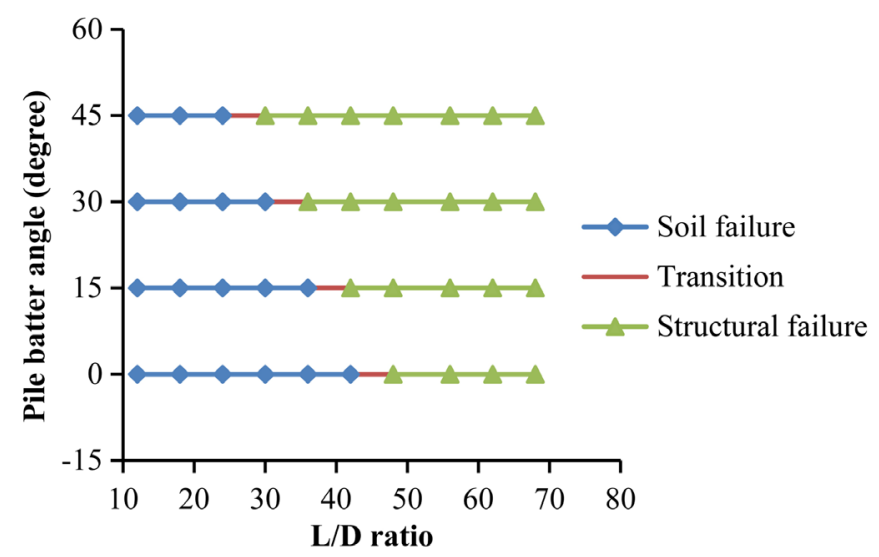

Figure 6. Mode of failure for different batter angles.

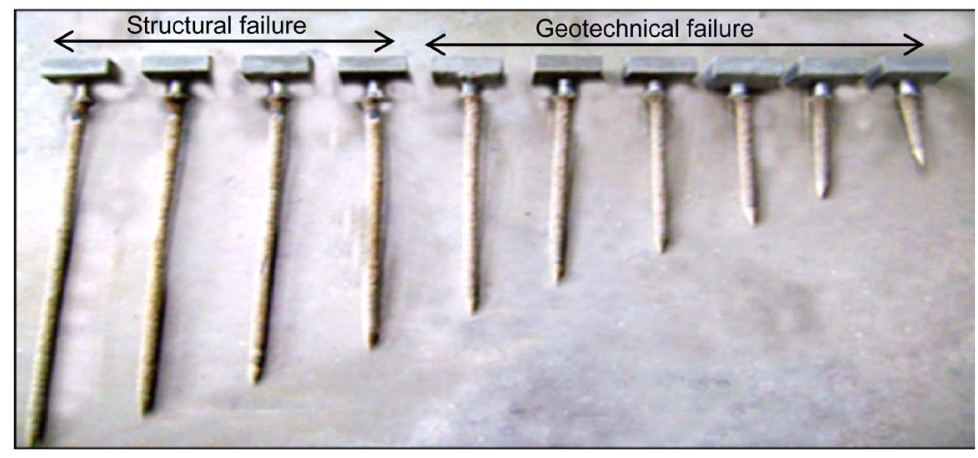

Figure 7. Mode of failure in case of vertical micropiles.

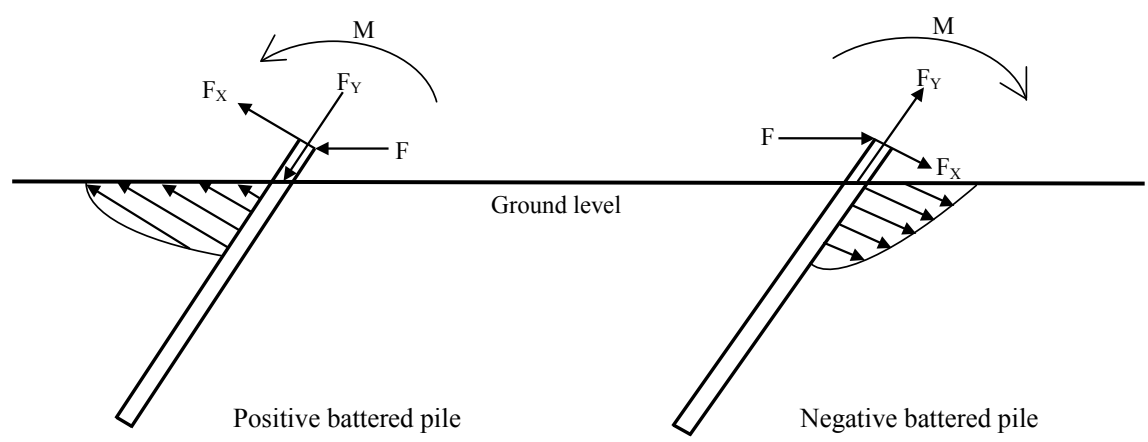

Figure 8. Positive and negative batter micropiles.

\section{Load (N)}

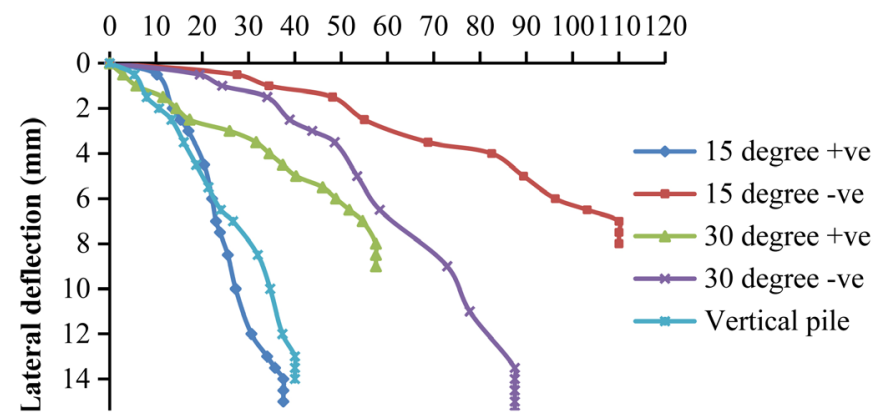

Figure 9. Lateral load-deflection behaviour of battered micropiles for L/D ratio of 42 . 
a given load, it can be seen that the lateral deflection measured at the ground surface was smaller for a negatively battered micropile than for a vertical micropile. Conversely, the lateral deflection was larger for a positively battered micropile than for a vertical micropile. This is due to the fact that there is limited lateral resistance for a positively battered micropile, but the resistance is greatest for a negatively battered micropile.

\subsubsection{Effect of Length to Diameter Ratio, L/D}

Lateral load-deflection behaviour of $15^{\circ}$ positive and negative batter micropiles for various L/D ratio are shown in Figure 10(a) and Figure 10(b). It is observed from this plot that from L/D ratio of 36 to $\mathrm{L} / \mathrm{D}$ ratio of 68 , the lateral load deflection plots falls in a close cluster with insignificant increase in ultimate lateral load. Similar observation is seen in Figure 11 (a) and Figure 11 (b) for $30^{\circ}$ positive and negative batter micropiles.

Figure 12 illustrates the effect of length diameter ratio, L/D on the ultimate

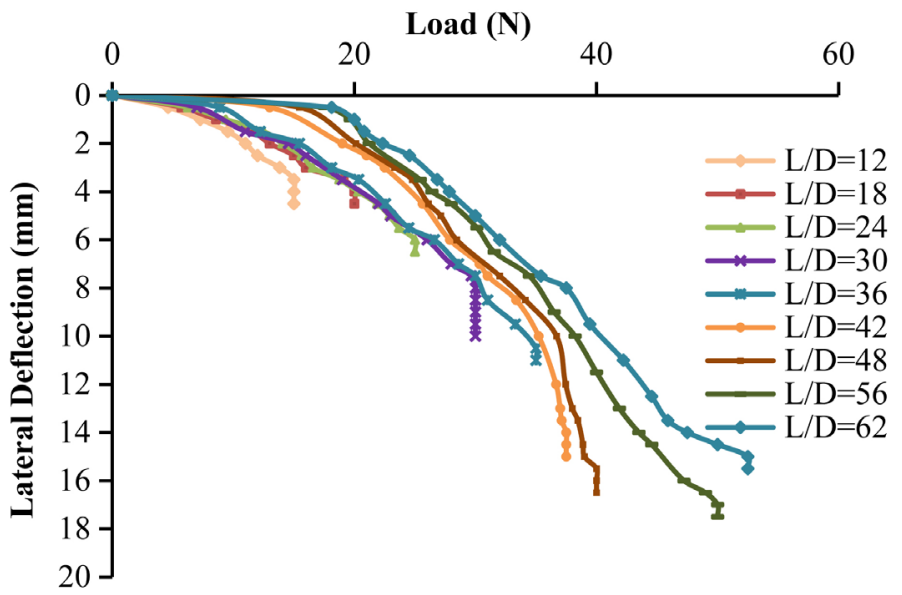

(a)

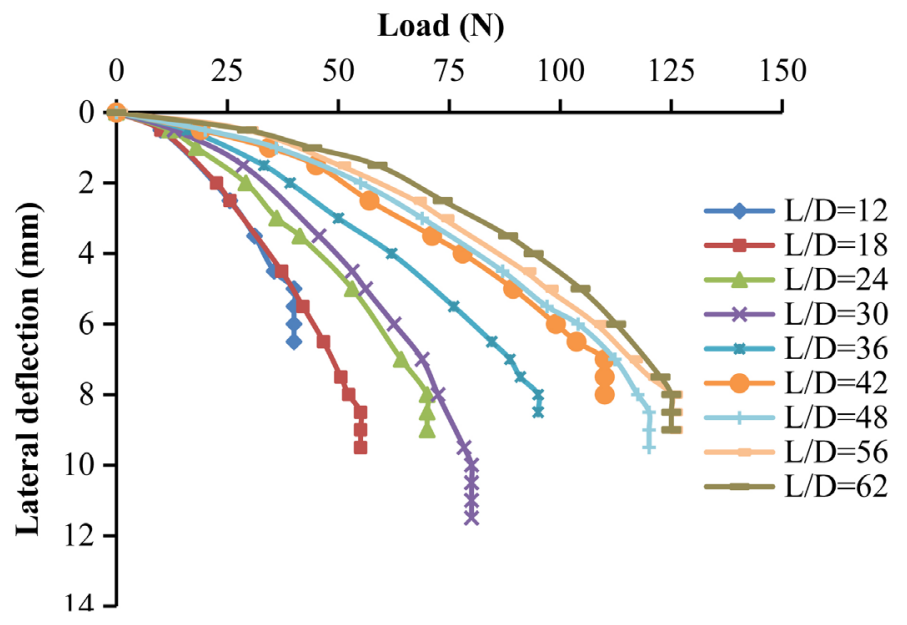

(b)

Figure 10. (a) Lateral load-deflection behaviour of $15^{\circ}$ positive batter micropile for various L/D ratio; (b) Lateral load-deflection behaviour of $15^{\circ}$ negative batter micropile for various $\mathrm{L} / \mathrm{D}$ ratio. 


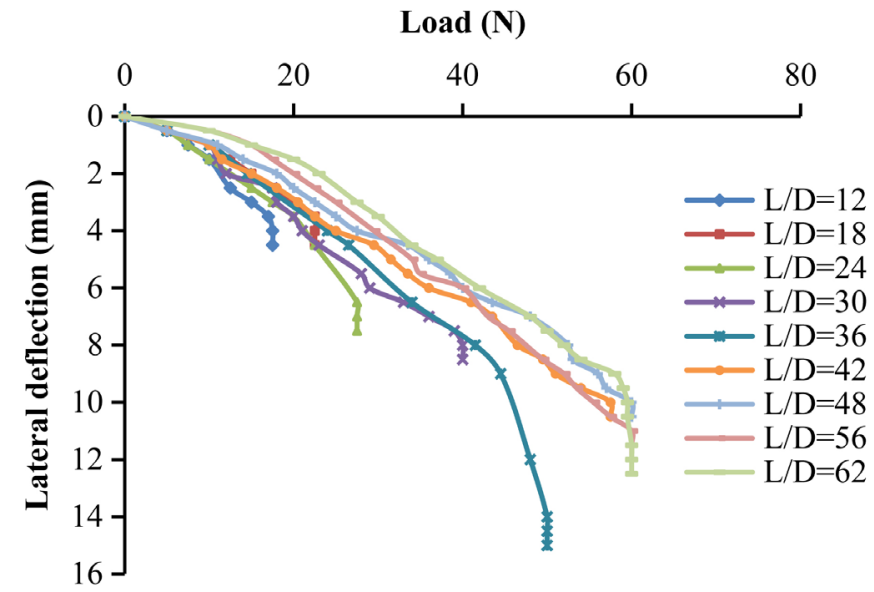

(a)

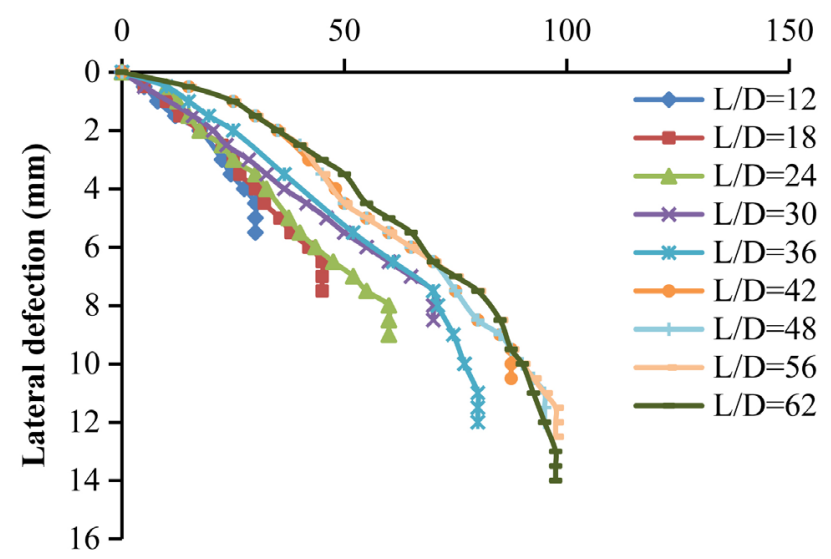

(b)

Figure 11. (a) Lateral load-deflection behaviour of $30^{\circ}$ positive batter micropile for various L/D ratio; (b) Lateral load-deflection behaviour of $30^{\circ}$ negative batter micropile for various $\mathrm{L} / \mathrm{D}$ ratio.

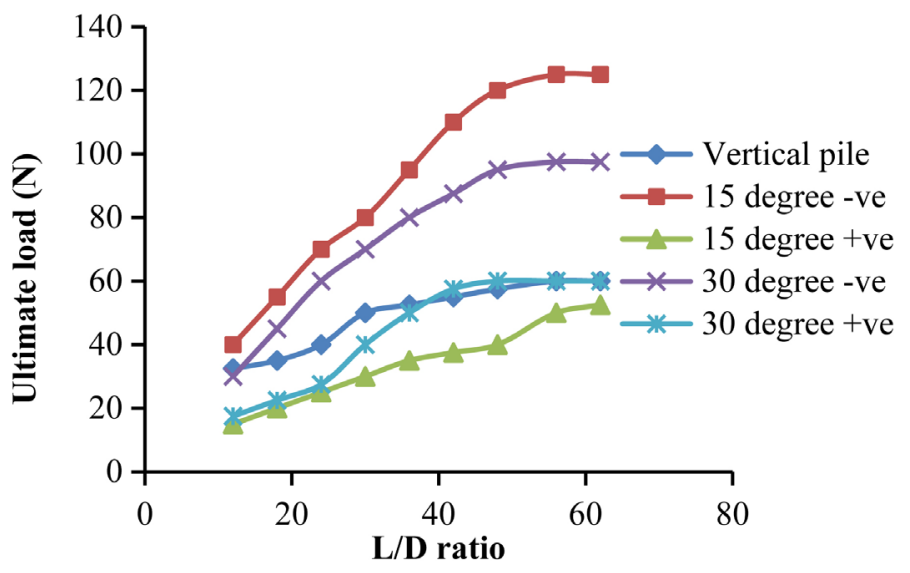

Figure 12. Ultimate lateral load versus L/D ratio.

lateral load. For the vertical micropiles subjected to lateral loading, the ultimate lateral load is found to increase with increasing $\mathrm{L} / \mathrm{D}$ ratio upto a $\mathrm{L} / \mathrm{D}$ ratio of 30 , 
above which the increase becomes relatively insignificant. Sharma (2011) reported similar behaviour. This observation agrees with Polous \& Davis (1980) approach for conventional vertical pile that increasing the pile length beyond a particular length will not lead to an increase in ultimate vertical load.

In case of the positive battered micropiles, the ultimate lateral load is found to increase with increasing $L / D$ ratio upto a $L / D$ ratio of 42 above which the increase is not very significant. Figure 11(a) presents the lateral displacement of micropile versus applied lateral load for $30^{\circ}$ negative batter angle. The results presented in this figure and in Figure 12 show that micropile capacity increases with length upto L/D ratio of 48 , after which the increase in ultimate lateral load with further increasing the length of micropiles is negligible. Hence it is observed that beyond a particular length the micropile behaviour is found to be similar. This is because beyond a particular length the pile behaves as a long pile, where cumulative passive resistance developed at the lower part of the pile is quite high due to which the pile cannot rotate and the pile fails by structural failure of the pile.

\subsubsection{Influence of Pile Batter Angle}

The influence of the batter angle of the micropile on the ultimate lateral load is illustrated in Figure 13 where it is seen that micropiles with a negative batter have more lateral resistance than micropiles with a positive batter. Based on the results of the experiments, it is clear that the ultimate load is more sensitive to the direction of batter (Figure 13) than it is to the slenderness ratio.

It is reported that negative batter piles offer more lateral resistance than positive batter piles. This is explained by the fact that the soil reaction at ground level is zero for a positive batter pile and maximum for a negative batter pile, indicating that the upper soil support in a negative batter is enormous so that negative batter pile has larger lateral resistance. Even in case of micropiles, ultimate lateral resistance is found to be higher at $15^{\circ}$ and $30^{\circ}$ negative batter pile compared

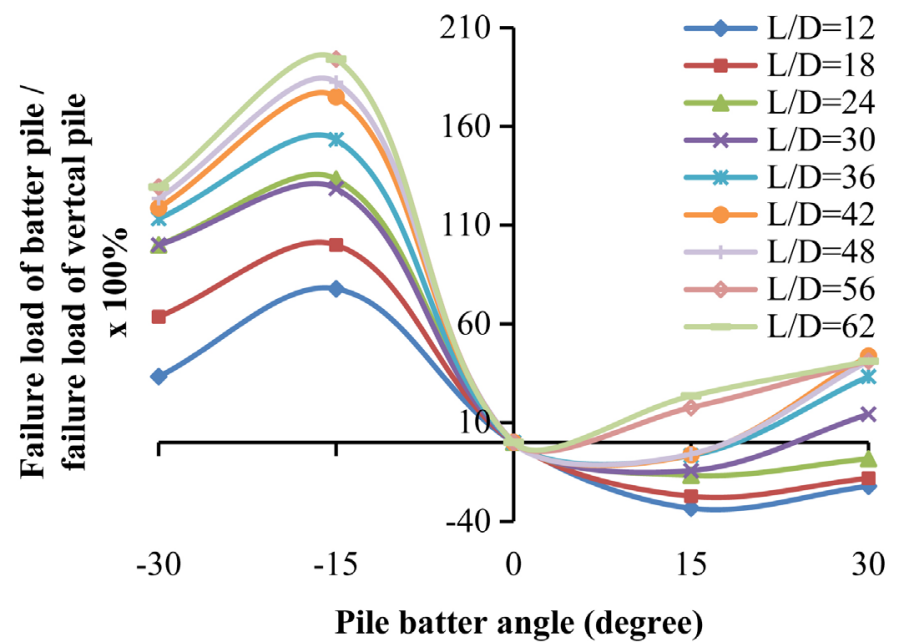

Figure 13. Percentage variation of batter pile load with respect to vertical versus pile batter angle. 
to vertical and positive batter pile. $15^{\circ}$ negative batter is consistently showing higher lateral loads than $30^{\circ}$ negative batter. Positive batter is not showing significant decrease or increase compared to vertical piles. Based on the experimental results for the micropiles with a $15^{\circ}$ and $30^{\circ}$ negative batter the ultimate load is more sensitive to the slenderness, $\mathrm{L} / \mathrm{D}$ ratio than it is for the vertical micropiles.

Numerical study on the effect of inclined micropiles was studied by Manfared, 2012. The study was carried out using nonlinear FEM analysis. The investigation was on the behaviour of an inclined micropile subjected simultaneously to lateral load and bending moment. The results indicated that negative micropiles have higher load capacity than positive micropiles. It was further found that increasing the inclination angle in negative micropiles led to increase in lateral load capacity compared to vertical micropiles. In positive micropiles increasing the inclination angle upto $30^{\circ}$ had contrary effects, in that it led to decrease in lateral load capacity compared to vertical micropiles. Increasing the inclination angle more than $30^{\circ}$ had no notable effect on the micropile soil system. It was also observed by them that increasing the length of micropile has a less effect on soil-micropile system response. The observation of the present study has been found to agree with the numerical study of (Manfared, 2012).

\subsubsection{Mode of Failure}

Broms (1964) identified two types of failure of piles in cohesionless soils subjected to lateral loads. One is failure of soil i.e., geotechnical failure and the other is fracture of piles by formation of plastic hinges or structural failure. The first type is observed by a short or rigid pile. The second type is observed in case of a long or flexible pile, where cumulative passive resistance developed at the lower part of the pile is quite high due to which the pile cannot rotate and structural failure occurs at the point of maximum bending moment. In this study, both geotechnical and structural failure of the micropiles were observed during the experiment. For the vertical micropiles and the micropiles with a positive batter of $15^{\circ}$ and $30^{\circ}$, subjected to lateral loading, geotechnical failure was observed for micropiles with a L/D ratio of $12,18,24$ and 30 and structural failure was observed for the remainder of the micropiles. For the micropiles with a negative batter of $15^{\circ}$ and $30^{\circ}$ only two piles with L/D ratios of 12 and 18 failed by geotechnical failure, whereas the remainder of the piles failed by structural failure. The mode of failure for different batter angles subjected to lateral loading is shown in Figure 14. A photograph illustrating the mode of failure for the micropiles with a $30^{\circ}$ negative batter is shown in Figure 15.

In reviewing the results of the experiments, the phenomenon that fewer micropiles with a negative batter underwent geotechnical failure is explained by the fact that the soil resistance is greater at ground level for piles with a negative batter. Moreover, the mode of failure or whether the piles will behave as short rigid piles or long flexible piles is a function of the angle of batter, direction of batter and $\mathrm{L} / \mathrm{D}$ ratio of the micropiles. 


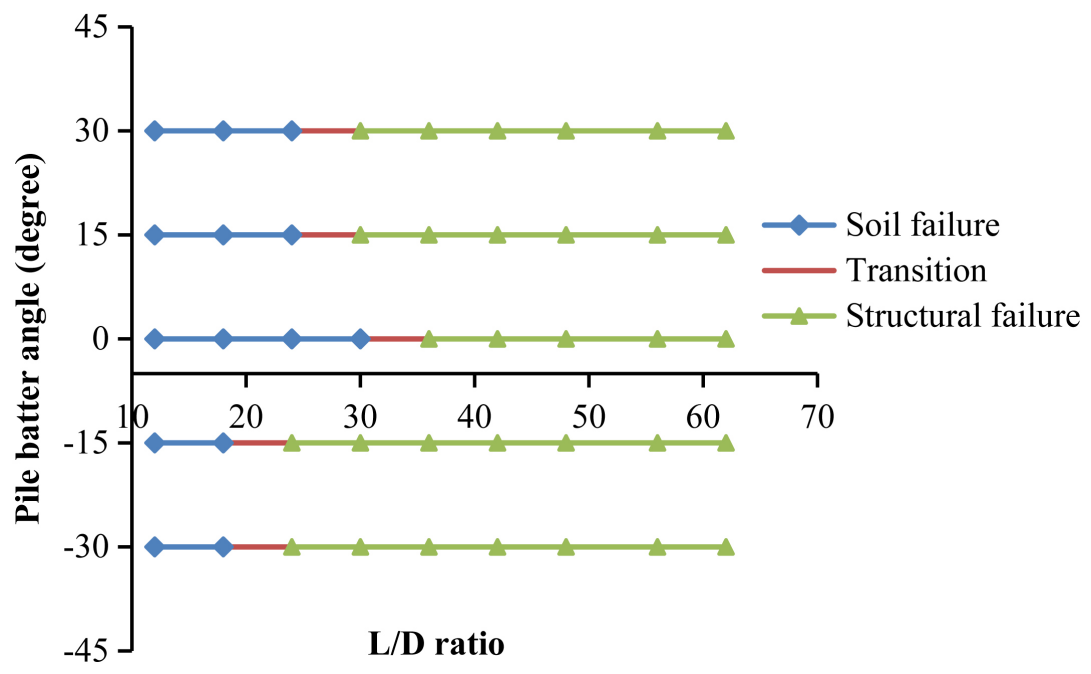

Figure 14. Mode of failure for different batter angles subjected to lateral loading.

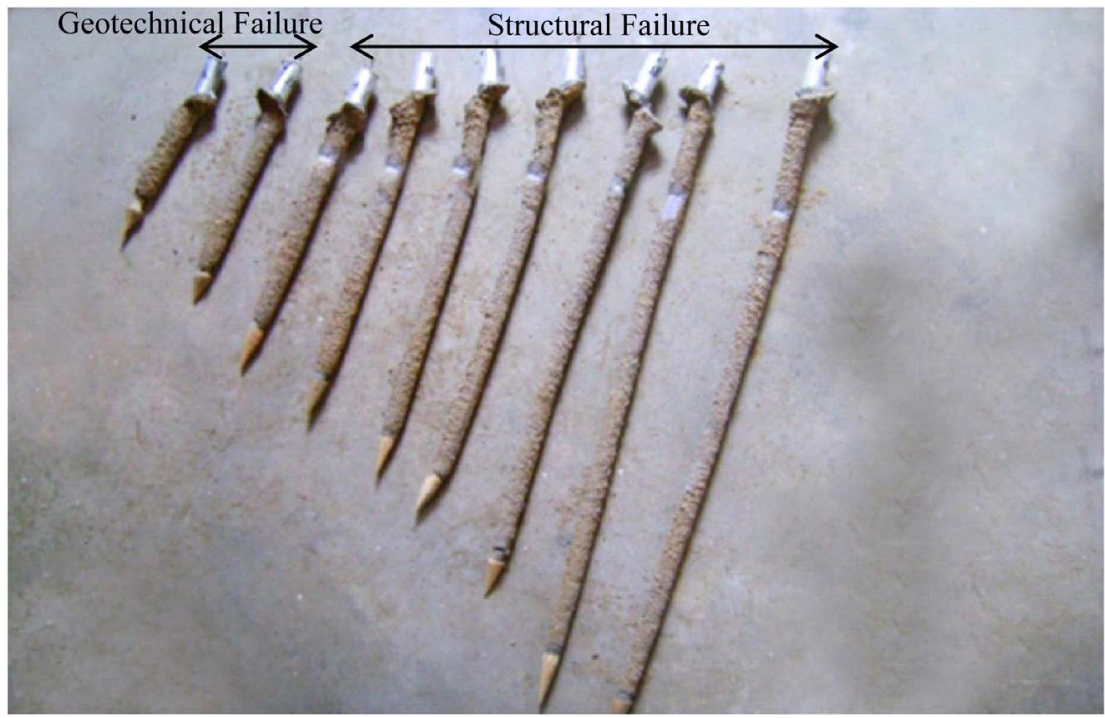

Figure 15. Mode of failure for micropiles with a $30^{\circ}$ negative batter subjected to lateral loading for varying $\mathrm{L} / \mathrm{D}$ ratio.

\section{Conclusion}

An experimental model study was conducted to assess the effect of the main parameters on the performance of the battered micropiles. For battered micropiles subjected to vertical loads, the ultimate load carrying capacity of the micropiles was found to increase with increasing L/D ratio upto $30^{\circ}$ batter. Upto $30^{\circ}$ batter angle, there is no significant increase or decrease of the ultimate vertical pile load with respect to the vertical pile. The mode of failure is found to be a function of the pile batter angle and L/D ratio of the piles for vertical loading. For the vertical and battered micropiles subjected to lateral loading, the ultimate lateral load was found to increase significantly for increasing L/D ratios upto L/D ratios of 30, 42 and 48 for vertical, positive battered and negative battered piles respectively. Beyond it the increase in ultimate lateral load for increasing L/D ratios 
was found to be insignificant for all the three cases. The ultimate load is more sensitive to the length to diameter, $\mathrm{L} / \mathrm{D}$ ratio for the micropiles with a $15^{\circ}$ and $30^{\circ}$ negative batter than it is for the vertical and positive batter micropiles. The ultimate lateral resistance was found to be greater for the micropiles with a $15^{\circ}$ and $30^{\circ}$ negative batter compared to the vertical and positively battered piles. The mode of failure of the micropiles is a function of the angle of batter, direction of batter and the $\mathrm{L} / \mathrm{D}$ ratio of the micropiles, to varying degrees of sensitivity, for both loading in the vertical and lateral directions. However these observations are for model testing in sand. These are to be verified further with field testing in sand and in other cohesive soils to understand better the behaviour of battered micropiles in soil.

\section{Conflicts of Interest}

The authors declare no conflicts of interest regarding the publication of this paper.

\section{References}

Benslimane, A., Juran, I., Hanna, S., \& Drabkin, S. (1998). Seismic Behaviour of Micropile System. Proceedings of Sessions of Geo-Congress, Boston, 18-21 October 1998.

Broms, B. (1964). Lateral Resistance of Piles in Cohesionless Soil. J.S.M.F.D., ASCE, 90, $123-156$

Bruce, D. A. (1995). Small-Diameter Cast-in-Place Elements for Load-Bearing and in Situ Earth Reinforcement. In P. Xanthakos, W. Abramson, \& D. A. Bruce (Eds.), Ground Control and Improvement (pp. 406-492). New York: John Wiley and Sons.

Juran, I., Benslimane, A., \& Hanna, S. (2001). Engineering Analysis of Dynamic Behavior of Micropile System. Transportation Research Record, 1772, 91-106. https://doi.org/10.3141/1772-11

Lizzi, F. (1978). Reticulated Root Piles to Correct Landslides. ASCE Convention and EXposition, Chicago, 16-20 October 1978, 25 p.

Lizzi, F. (1982). The Pali Radice (Root Piles). Symposium on Soil and Rock Improvement Techniques including Geotextiles Reinforced Earth and Modern Piling Methods, Bangkok, 29 November-3 December 1982, D-1-1-D-1-21.

Lizzi, F. (1983). The Reticolo di Pali Radice (Reticulated Root pile) for the Improvement of Soil Resistance, Physical Aspects and Design Approaches. VIII ECSMFE, Helsinki, 521-524.

Manfared, S. D. (2012). Numerical Study on the Behavior of Inclined Micropiles. Proceedings of the 37th Annual Conference on Deep Foundations, Houston, 16-18 October 2012 .

Mitrani, H., \& Madabhushi, G. P. S. (2005). Centrifuge Tests Investigating Inclined Grout Micropiles as a Method of Liquefaction Remediation for Existing Buildings. Proceedings of ASCE Geo-Frontiers Conference.

Noorzad, R., \& Saghaee, G. (2009). Seismic Analysis of Inclined Micropiles Using Numerical Methods. Contemporary Topics in Deep Foundations, 406-413.

https://doi.org/10.1061/41021(335)51

O’Neil, M. W., \& Pierry, R. F. (1989). Behaviour of Mini-Grouted Piles Used in of the International Conference on Piling and Deep Foundations, London, 101-109. 
Polous, H. G., \& Davis, E. H. (1980). Pile Foundation Analysis \& Design. New York: John Willey \& Sons.

Sabini, G., \& Sapio, G. (1981). Behaviour of Small Diameter Piles under Axial Load. $X$ ICSMFE, 2, 823-828.

Sadek, M., \& Isam, S. (2004). Three Dimensional Finite Element Analysis of the Seismic Behaviour of Inclined Micropiles. Journal of Soil Mechanics and Earthquake Engineering, 24, 473-485. https://doi.org/10.1016/j.soildyn.2004.02.002

Schlosser, F., \& Juran, I. (1979). Design Parameters of Artificially Improved Soils. ECSMFE, 5, 197-225.

Sharma, B. (2011). A Model Study of Micropiles Subjected to Lateral Loading and Oblique Pull. Indian Geotechnical Journal, 41, 196-205.

Soliman, N., \& Munkofh, G. (1988). Foundation on Drilled and Grouted Minipiles. A Case History. Proceedings of the 1st International Geotechnical Seminar on Deep Foundations on Bored and Auger piles, Ghent, 363-369.

Ting, W. H., \& Nithiraj, R. (2000). Underpinning a Medium Rise Building with Micropiles-A Case History. Geotehnical Engineering Journal of South East Asia Geotechnical Society, 31 .

Yamane, T., Nakata, Y., \& Otani, Y. (2000). Efficiency of Micropiles for Seismic Retrofit of Foundation System. Proceedings of the 12th World Conference on Earthquake Engineering, Auckland, 1-8. 